JETAL: JOURNAL OF ENGLISH TEACHING \& APPLIED LINGUISTICS

$\begin{array}{llll}\text { VOLUME } 2 & \text { Number } 2 & \text { Page 62-67 } & \text { e-issn:2714-9811 }\end{array}$

\title{
An Analysis of Lexical Cohesion on the Students' Writing
}

\author{
Usman Sidabutar \\ English Language Department of FKIP Nommensen HKBP University \\ Email: usman.sidabutar@uhn.ac.id
}

\begin{abstract}
This research aims at finding lexical cohesion in high and low-graded lexical cohesion types on the students' narrative writing. The researcher wants to reveal the reasons why the writing problems exist in lexical cohesion and also to find out what way that the students will use to solve the lexical types in writing narrative text. The present research uses the types of lexical cohesion as proposed by Halliday and Matthiensen (2014). The lexical cohesion items consist of repetition, synonymy, antonymy, hyponymy, and meronymy. The data of this research are derived from students' writing through writing research papers. This research was conducted in qualitative. The results show that repetition becomes the highest occurrence in the students' writing as there are 240 occurrences $(64 \%)$ in total types of lexical. Nevertheless, the least kind of lexical cohesion is hyponymy. There are only 20 occurrences $(6,6 \%)$. It can be seen that the meaning relation in the text occurs among the six types of lexical cohesion to make cohesive text. Besides that, the context of the text itself also refers to coherent text. It means that the text should consist of interrelated sentences to achieve good unity. Both are related to each other in creating well-structured text. The students were sometimes difficult to connect one word with other words. There might be a reluctance of translating the classification of the real words of EFL. Pedagogically, the students need to get studying vocabularies professionally to upgrade the stage of English into an advanced level especially in teaching English writing ability. It was recommended to teachers or lecturers to take an in-depth look at the EFL learners' problems in writing English more than and the English lecturers practice the prompt way to master vocabulary as the core of enhancing the writing quality
\end{abstract}

Keywords: Writing; Cohesion; Lexical cohesion; Narrative text

\section{Introduction}

English to its importance brings to the international language of English learning. It is an alternative language to communicate or interact with others from different countries which has the national language as well as various kinds of traditional languages; Indonesia is also one of the countries which had learned English.

Writing an essay in a foreign language can be a difficult task for some EFL students. Nunan (1999)stated that creating an intelligible piece of writing is a huge challenge, especially in a second language. Many ESL or EFL students encounter difficulties in both expressing and uniting their ideas, and translating their ideas into a meaningful text (Richards and Renandya, 2002, cited in Ghasemi, 2013). Specifically in Indonesia, researches into EFL learners' writing exposed that students find some problems when transfer ideas from L1 to L2 because of dissimilarities rules between Bahasa Indonesia and English, and the lack of knowledge and linguistic structures in English (Ariyanti, 2016; Rahmatunisa, 2014). These problems affect some EFL students have lack writing performance with the result that their writing becomes obstinate, and hard to take the information and catch the meaning of their writing

Writingin English has a more purely pedagogical role. It reinforces the learning which goes on through the medium of listening, speaking, and reading skills. In writing skills, the teacher often finds errors in students' writing for example grammatical problems. The students are difficult to write correct grammar besides that they are lack of designing vocabularies. Language learning off foreign language cannot be separated by the rules of grammar besides vocabulary. According to Setiyadi (2006:40), language learning is evaluated by giving items of Lexical units to the class, and scores are based on the right answers of the test. Based on the background of the study, the researcher researches to find out the types of lexical cohesion errors made by the students in writing and the objective of the study is to find out the most dominant of lexical cohesion are used on the students' writing. This study is focused on an analysis of Lexical cohesion as found in writing exposition 
Writing is an important part of many standardized tests. Writing is a fundamental part of many careers. In addition to full-time writers such as novelist, scriptwriters, and lyricists and many other Nunan (2003:106) describes that writing is a teachable and learnable skill, and the instructor can play an invaluable role in making this skill an enjoyable one.

Stott and Avery (2001:235) state writing is one way of making meaning from experience for ourselves and others. Good writing begins with understanding how to construct and use effective sentences and paragraphs. Moreover, According to Harmer (2004:33), writing is frequently useful as preparation for some other activities, in particular when students write sentences as a preamble to discussion activities.

Writing is not as simple as imagined. According to Knapp and Watkins (2005:15), writing is an inscription. It is language in the spatial medium.

Harris in Indriani $(2015 ; 18)$ stated in his book Testing English as a Second Language. The components of writing should be followed with the components of content which consists of the substance of writing and the ideas expressed. Furthermore, the form used, it is about the organization of the content. The employment of grammatical form, syntactic pattern, the structures and lexical items to give a particular tone or flavor to writing includes the diction uses to construct sentences by sentences to be a good paragraph. Fifth is mechanic, the use of the graphic convention of the language. From the definitions above, they can be concluded that writing is a complex process of forming words coherence or making marks on a flat surface to explore thoughts and ideas as a representation of language in a textual medium

Similar studies were conducted by Tonder Susan (1999), who took the data source from the students' academic writing. The present study focuses on lexical cohesion in 2 short stories by W. Somerset Maugham, Mr. Know-All, and the Outstation. The present study aims to find out (1) the lexical cohesion and (2) the lexical ties in the two short stories. The results of the tests on the hypotheses and interpretations of each were given. The most noteworthy results were the correlations between derivational ties and error density with the perceived coherence of the texts as well as with their achievement levels and the relationship between these achievement levels and coherence. Although correlational tests can never determine a causal relationship between variables, the results of these tests have helped to increase our understanding, about one set of student academic writing data, of the complex relationship between cohesion, coherence, and academic achievement. Particularly, at Jambi University, one study that has ever been conducted on cohesive devices at the English department was the one done by Tristasariin 2015. Her research in EFL writing was done to investigate the variation of the cohesive device and the problem in using cohesive devices in students' writing. In line with her, the present study also wants to investigate cohesive devices but in different areas of concern and objectives. The present study specifically focused on lexical cohesion found in high graded and professionals use writing on a daily job. Writing is already and will continue to be an important part of our daily

life

low graded students' argumentative essays of thirdsemester students of the English Department in Jambi University. The study is interested to see semantic variation made by students through their vocabulary choices to create a good piece of writings.

One of the basic competencies that must be possessed by students is presenting events, sequence of events, and messages in writing orally and in writing. These basic competencies are contained in the courses that must be completed in the semester one to the third semester which will be the capital for writing a thesis as a requirement for completing undergraduate level education.

Writing is the most dominant academic act which is disliked by many students because the discourse is telling. Students tend to prefer reading stories rather than writing, let alone writing texts related to scientific works that are still imperfect. This can be seen in the research conducted by Ghufron. Ghufron (2012) examined "Cohesion Tools in Student Writing Discourse: Their Development and Errors". Ghufron still finds some mistakes in the narrative essays compiled by students. The errors found were related to the use of cohesion tools, namely the use of conjunctions, ellipsis, synonyms, meronyms, and repetitions. So, it is necessary to have teaching materials that are used to deepen students' knowledge related to lexical cohesion. Widodo and Jasmadi (in Lestari, 2013: 1) suggest that teaching materials are a set of learning tools or tools that contain learning materials, methods, limitations, and ways of evaluating that are designed systematically and attractively in order to achieve the expected goals, namely achieving competencies or subcompetencies with all their complexities.

Cohesion as a tool for writing integrity is shared into two kinds, namelygrammatical cohesion and lexical cohesion(see Halliday and Hasan, 1976). Grammatical cohesion is a marker of cohesioninvolved the use of linguistic elements.This tool is used to connect ideas between sentences. In other words, connectedness between sentences expressed with grammatical elements. Grammatical cohesion is characterized by reference, substitution, ellipsis, and conjunctions. Cohesion in discourse is not determined only by the presence of a grammatical tool but also by the existence of a lexical relationship. Repetition of words or phrases, for example, can be binding one sentence with another sentence. Tools lexical cohesion in between reps, synonyms, antonym, hyponym / hyperonym, collocation, and isotopy(Halliday and Hasan, 1976; Tarigan, 1987; Djayasudarman, 1994; Rani, Arifin, and Martutik, 2006; Octavianus, 2006; Sudaryat, 2009; Zaimar and Harahap, 2011).

Cohesion has an important role in produce a complete and coherent text of the exposition. Cohesion is not only about form(grammatical cohesion), but also related to meaning (lexical cohesion). Cohesive exposition text will show a clear relationship between 
units one form and another, so that the meaning of the text to be clear and complete.

Zulianti (2018) in her research regarding the analysis on the use of lexical cohesion on the students' writing tried to give several comments to the students towards their writings. Inthe discussion of repetition, the students need to pay attention on how they repeat some words in their writings. Ashas been applied in the research findings, some words are repeated by the students which make their writing are not good enough to be read. It tends to be monotone. In this case, the students can use reference to replace the same words to avoid monotonous

One will be conducted to this research is to enable the writers to have high capacity of vocabulary designed in order to be able to apply which words should be used in their writings. In order to be able to constructsignificant writings, the students also need to require the capability to grab the meaning of word with others words or sentence with other sentences. The constructionchain among words with other words in target meaning play a maindecree in the result of coherence, meanwhile the relation meaning between each words in a writings plays a major rule in the achievement of cohesion.

Lexical cohesion apart from being supported by aspects of grammatical cohesion of discourse must be supported by aspects of lexical cohesion. Lexical cohesion or lexical merging is the relationship between parts of discourse or in other words lexical cohesion is the relationship between elements in discourse in semantically. Dharma (2014: 59) has two ways to achieve the lexical aspect, namely repetition (repetition) and collocation. Repetition is a marker of lexical cohesion in the form of repetition of lingual units which are considered important to emphasize the text. Complete repetition or full repetition is unit repetition in the sentence as a whole without changing the form but this usage must have limitations so as not to be redundant.

Repetition with is another name for the same object or thing which functions for an equivalent meaning relationship between one lingual unit and another lingual unit in discourse. Repetition with is a kind of relationship between words that is in the form of a top-down. In the context of discourse, hyponym has an important role in forming a discourse that has collocations or sanding words that have certain associations in using the choice of words that tend to be used.

Lexical cohesion refers to the relationship between or among words in a text. It is concerned with the content words and primarily related to that field. The field is discovered through the content words within a text. This field tends to have specialized vocabularies and tends to engage in specialized activities. Hassan (1984:320) and Halliday and Mathienssen (2014) present five categories of general lexical cohesion:

a. Repetition / Re-iteration (including inflection and derivation), is the act or process instance of repeating or being repeated. Example: Miley is in the singing contest on Sunday. Everyone believes that she will win the

b. Synonymy (similarity of meaning), is a word having the same or nearly the same meaning as another word or other words in a language. For example, I am taken to the clinic - I am taken to the hospital

c. Antonyms (opposite or contrastive meaning). Antonymy is a word having a meaning opposite that of another word. For examples: Male-female

d. Hyponymy is the relation between two words in which the meaning of one of the words includes the meaning of another word. For example, She'll win a trophy. The award makes a great happiness

e. Meronymy (whole-part relation), is a figure of speech in which one word or phrase is substituted for another with which is close. For example Linguistics- discourse analysis, language acquisition, and sociolinguistics.

As a basic skill in English writing also has some purpose. According to McMahan in Sarinten (2010: 6364) the purpose of writing is to express the writer's feeling. It means the writer wants to express his feeling and thought through the written form, as in a diary or a love letter.

a. The writer intends to entertain the reader through written form, and he usually uses authentic materials. It is called literary writing.

b. To inform the readers

c. It is used to give information or explain something to the readers. It is a kind of informative writing.

d. To persuade the readers

e. The writer wants to persuade or convince the readers about his opinion or concept or idea. It is called persuasive writing.

According to Hayland (2002: 15 ) Genre is a term for grouping texts together, representing how writers typically use language to respond to recurring situations. Every genre has several features that make it different from other genres: each has a specific purpose, an overall structure, specific linguistic features, and is shared by members of the culture.

For many people, it is an intuitively attractive concept which helps to organize the common-sense labels we use to categorize texts and the situations in which they occur. There are some kinds of reading a text such as narrative, recount, procedure, report, descriptive, spoof, anecdote, etc. Pardiyono (2007:31) describes that there is some importance of learning Genre in Writing, they are: Genre serves as the frame of reference in which particular task to be oriental. It is closely tied with the discussion of communicative purpose (intention) and conventionalized format (rhetorical structure) of a text and linguistic realization. Thus, it provides a reference for a particular communicative purpose to achieving stages of the rhetorical structure to cover and linguistic features to stick, by which the reader's expectation can be met effectively.

The narrative text is one of the texts that should be mastered by senior high school students. The narrative is a kind of text to amuse, entertain, and deal with actual or vicarious experiences in different ways. It deals with problematic events which later lead to a crisis 
and end with a resolution as closing. In learning narrative text, the students must know the structure of the text, the plot of the story-when crisis arises and what the resolution is. That is why the teacher must also focus on how to develop the text to become a good sequential story. A narrative is a meaningful sequence of events told in words. It is sequential in that the events are ordered, not merely random. The sequence always involves an arrangement in time (and usually other arrangements as well). A straightforward movement from the first event to the last constitutes the simplest chronology Kane (2000:366). In writing narrative text, the students need to know the conventions above: conventions in writing and conventions in narrative text. The students have to use correct organization, appropriate vocabulary, language use (grammar), and mechanics besides they have to develop the text into a good narrative story chronologically (content) based on the plot structure and language features. The teacher's job is still giving them understanding about those conventions and more time for practicing. While, Anderson and Anderson in Indriani (2015:25-26) state that there are some steps to construct a narrative text, they are:

a. An orientation (can be a paragraph, a picture, or opening chapter) in which the narrator tells the audience about who is in the story, when the story is taking place, and where the action is happening. It simply introduces the characters of the story, how the story begins, and where the story takes place. It is very important to attract the readers 'attention in the first paragraph. It will show the quality of the story itself.

b. A complication that sets off a chain of events that influences react what will happen in the story. A complication is one of the important parts of narrative text. Without complication, narrative text cannot be an interesting story to be read, it just a story without sense or taste. The problem makes the story more interesting for asequence of events where the characters react to the complication or problem from the story. It consists of some events in the story in which the characters react and face the problems that occur. Detail of each event will show in this part, every detail of events makes the story alive. It shows how the main character or other characters solve the complication and problems. It shows how the writer ends the story.

c. A coda that provides a comment or is morally based on what has been learning from the story (an optional step). Some writers do not include coda because it was optional, so that, it sometimes occurs.

In conducting research, theories should be explained and clarified in the reality of the research design. This is considered to be a very important aspect in conveying the ideas. The concepts should be clear to have the same perspective of implementation in the field in the other words, it is important to discuss the concept used or discussed so that the reader would get the point.

Error is something done wrong by the students because they don't know what is correct. Making an error is a part of the language. It will always occur when they try to speak or write the target language. According to Dulay (1982:138) stated that error is "the flawed side of learner speech or writing". They are those parts of conversation or composition that deviate from some selected norm of mature language performance. It means that the area of learners' error can be found in the spoken such as in their conversation and writing.

\section{Method}

The research design of this research is qualitative research because the results of this study identified and analyzed students' lexical cohesion in narrative text. According to Creswell (2009:4) "qualitative research is a means for exploring and understanding the meaning individuals or groups ascribe to a social or human problem." The work way of descriptive qualitative is collecting the data, arranging the data, and interpreting the data. Qualitative research is concerned with description. The analysis was based on the data taken from the students' writing taken from the third semester of the English Department of HKBP Nommensen University Medan. The object of this study is the students of the fourth semester which consists of two groups (A, B). At least there are 40 students in each group. The writer chooses thirty (30) students from groups A and B as the object of the research. To get the data, there are many ways as observation, interview, documentation, and a test technique. For collecting the data for this research, the researcher runs observation. Observation is the direct watch at a research object to look at activities that are done in detail (Ridwan, 2007: 76). The researcher gathers the information about the teaching and learning process by conducting a classroom learning process and presenting the topic development of action. The writer puts the activities which have been done by selecting thirty (30) students from group A at the fourth semester as the participants of this research, giving the topic of the writing for the students as Restaurant, Mall, Market, Shopping, Holiday, Travelling, Hiking, Jogging, Cinema, Hospital, Digitalization Era, Hotel, Public Transportation, Covid19, and Beach. Having the data been collected, the researcher organized properly all the classification of lexical cohesion types based on the clauses. Classifying the types of the lexical cohesion found of the text is the final way to count the percentage of the result.

\section{Finding}

Lexical cohesion is the cohesive effect achieved by the selection of vocabulary. For the present study, lexical cohesion consists of repetition, synonymy, subordinate, antonym, hyponymy, and meronymy as the summarizing of taxonomy proposed by Halliday and Hasan(1976, 1989) and Halliday and Mathienssen (2014).

Generally, all types of lexical cohesion are found in both high and low-graded essays. Particularly, in high graded essays, repetition, synonymy, and hyponymy are found in all five high graded essays; antonymy is found in four high graded essays, and superordinate is only found in one high graded essay; also meronymy is found in two high graded essays. Whereas in low graded essays, repetition, synonymy, antonymy, and hyponymy 
are found in all five low graded essays; and each superordinate and meronymy is only found in one low graded essay.

From the table, the occurrences of each type of lexical cohesion which is found in high graded and low graded argumentative essays can be seen as follow:

\section{Repetition}

From five high graded and five low graded essays, repetition is found in all ten essays included lexical item and lexical unit. Repetition is mostly used from all types of lexical cohesion. Here is an example of repetition as follows.

a. "Actually, we have already known what's the main utility of using Android (6). Of course, Android is a mobile phone that can use many functions it makes users can still keep in touch with those live far away (8)."(L.2-3) Text 4

b. "The speaker repeats started twice. First started is the introduction, before explaining to the participants the real problem of equality gender, Emma began to take the listeners (reader) to define the gender-based understanding. Second, started refers to Emma's girlfriends which dropping out of sports team". (L.4-5 ) TEXT 1

The repetition of these words is caused by a move when the writers restate and elaborate their argument in the next sentence. And the repetition of some words shows continuity and relation between the previous sentence and the next sentence.

\section{Synonymy}

Synonymy occurs when lexical items are identical and have the same meaning. Synonymy may not be in the same word class such as cheered (verb) - applause (noun) (Halliday revised by Matthiessen, 2014). In another word, one lexical item can be substituted with another because it has a similar meaning or has a related meaning. Synonymy is found in all high graded and low graded essays. Salkie (1995) stated that one reason to use synonymy is to avoid the use of repetition many times which can be boring in writing. However, unlike repetition which has a lot of number occurrences, the use of synonyms is only pretty less than repetition. here is an example of synonymy as follows.

"The first is the farmer nowadays is not only improve the large land but also the wide plant and quality of land because. (L.4) text 3

\section{Hyponymy}

Hyponymy occurs when a lexical item refers to its subclasses such as a chair, table, bed are 'kinds' (hyponyms) of furniture (Halliday, revised by Matthiesen, 2014). Hyponymy is found in both high and low-graded essays and the occurrence of hyponymy is pretty less than synonymy. Hyponymy found in both levels of essays is used to elaborate or clarified something general to be more specific by providing various kinds of general things. Hyponymy is common where a passage of text is being developed using elaboration (Halliday, revised by Mathienssen, 2014). "android has affected people in Indonesia in some ways (1). Today, we are influenced by many kinds of android (2). They are: Facebook, Twitter, Whatsapp andInstagram (3)." (L.6-7 ) text 2

\section{Meronymy}

Meronymy is a term, which refers to a partwhole relation. Or in another word, meronymy is 'be part of' (Halliday, revised by Mathienssen, 2014). For instance: root and plant are part (meronymy) of the tree. Meronymy just appears in two high-graded essays and one low-grade essay. One example of meronymy is found in one high-graded essay is West Java, as part of Indonesia. Here, the writer tries to give a picture of why software applications can be harmful to Indonesian by giving one case that happened in West Java as West Java itself is one of the provinces in Indonesia.

."The farmer takes care of the plant so that the roots can be harvested for natural medicine. (L.6-7 ) text6

Table 4.1.

The Result of Lexical Cohesion on the Students' Writing

\begin{tabular}{lcl}
\hline $\begin{array}{l}\text { Types of } \\
\text { lexical } \\
\text { Cohesion }\end{array}$ & Number & Percentage \\
\hline Repetition & 240 & 64 \\
Synonymy & 46 & 13 \\
Antonymy & 25 & 7.6 \\
Hyponymy & 20 & 6.6 \\
Meronymy & 28 & 8.8 \\
\hline total & 371 & 100 \\
\hline
\end{tabular}

Based on the data analysis, it can be concluded that the kind of lexical cohesion which is mostly used by the author is repetition is the most dominant as there are 240 occurrences (64\%) in total types of lexical. Nevertheless, the least kind of lexical cohesion is hyponymy. There are only 20 occurrences $(6,6 \%)$. It can be seen that the meaning relation in the text occurs among the six types of lexical cohesion to make cohesive text. Besides that, the context of the text itself also refers to coherent text. It means that the text should consist of interrelated sentences to achieve good unity. Both are related to each other in creating well-structured text.

Lexical cohesion becomes the obstacle for the students when writing text is concerned with text types. Repetitions become dominant in their writing due to having a less lexical capacity. Linguistic problems occurred when the students put the wrong lexical word or meaning to write a text.

\section{Conclusions}

The type of lexical cohesion which focuses on preparing students for all types of writing needed in the studying of their academic subjects may be classified as the instruction of English for Academic Purposes (EAP) which falls under the teaching of English for Specific Purposes (ESP). This is the type of teaching that might take place as part of a university course specifically designed to provide supplementary support for or development of students' academic learning, or which might be provided in the context of pre-university 
teaching aimed at establishing a "bridge" between previous schooling and tertiary level study.

\section{Suggestions}

It is advised that the students should master the competencies namely lexical cohesion for writing kinds of text. Also, it is suggested that lecturers help the students to overcome the lexical cohesion problems by providing text which not only concerned with the linguistic aspects but also concern fiction aspects. Moreover, it is recommended that the next researchers find the translation strategy, lexical cohesion method, and lexical cohesion technique which can be used to overcome the lexical cohesion problems. It was recommended to teachers or lecturers to take an indepth look at the EFL learners' problems in writing English more than and the English lecturers practice the prompt way to master vocabulary as the core of enhancing the writing quality

\section{REFERENCES}

Ahmed, Z.A (2012). The Lexical cohesion Knowledge of Lybian University Students.Bangor University.

Creswell, W.J (2009) Research Design Qualitative, Quantitative, and Mixed Method Approaches. USA: Sage Publication, Inc.

Dulay, et al..(1982). Language Two. New York: Oxford University Press.

Farokh, P. (2012). Raising Awareness of collocation in ESL/EFL classroom. Journal of Studies in Education 2(3): 55-74.

Ghasemi, M. (2013).An investigation into the use of cohesive devices in second language writings. Academy Publisher: Theory and Practice in Language Studies, 3(9), 1615-1623

Halliday, M.A.K. and Matthiessen, M.I.M. (2014).Halliday'sintroduction to functional grammar (4thed). USA: Routledge

Halliday, M.A.K.(1966).Lexis as a Linguistic Level. In Bazell, C. E.,Catford, J. C.,

Harmer, Jeremy. 2004. The Practice of English Language Teaching (4rd Edition).London: Longman Pearson.

Harmer, Jeremy. 2004. How to Teach Writing.London and New York: Longman.

Haswell, R. (1991). Gaining ground in college writing: Tales of development and interpretation. Dallas: Southern Methodist University Press.

Indriani, Etik. (2015) Improving students' writing narrative texts by using the combination of story sequencing cards and round table technique. thesis.States University of Malang: Malang

James, Carl. 1998. Errors in Language Learning and Use: Exploring Error Analysis. London: Longman. Inc.

Johns. M.Ann.(2002). Genre in The Classroom: Multiple Perspective, United States of America: Lawrence Erlbaum Associates.

Kane, Thomas. 2000. Essential Guide to Writing: New York: Oxford University Press

Knapp, Peter, and Watkins, Megan. 2005. Genre, Text, Grammar. Sidney: University of New South Wales
Lewis, M.(1997) Further development in the Lexical Approach, LTP.

Nasser, M. (2014).The Use of Lexical cohesions by Advanced Saudi EFL Learners in The UK and KSA. International Journal of English Linguistics 5(1):32:43.

Nunan, D. (2003). Practical English Language Teaching. Singapore: McGraw-Hill

Raimes, A.(1983). Techniques in Teaching Writing: Teaching Techniques in English as A Second Language.New York: Oxford University Press.

Ridwan .(2007). SkalaPengukuranVariabelvariabelPenelitian. Bandung: Alfabeta.

Saarinen, (2010).Improving Students' skills in writing narrative text through picture series.AThesis.Sebelasmaretuniversity Surakarta

Tonder, S.L.V (1999). An Analysis of Lexical Cohesion in W.Somerset Maugham's two short stories Mr. Know-Alland the outstation. https://core.ac.uk/download/pdf/43175636.pdf 